\section{ELECTROTHERAPY AT A BASE HOSPITAL.}

BY W. J. TURRELL, M.A., M.D. OXON.,

CAPTAIN, R.A.M.C. (T.F.), THIRD SOUTHERN GENERAL HOSPITAL; HLECTROTHERAPEUTIC PHYSICIAN, RADCLIFFE INTIRMARY, OXFORD.

VERY little attention has hitherto been drawn to the value of electrotherapy in the treatment of the sick and wounded in war time. The only published references to this subject of which I am aware occur in a paper, "Le Service de Physio. thérapie de l'Hôpital Militaire du Dey à Alger," by Dr. Hertz, Médecin Major de $1^{\text {re }}$ Classe, ${ }^{1}$ and in a paper entitled "La Physiothérapie des Blessés de Guerre," by M. Miramond de Laroquette. ${ }^{2}$ Both these papers are concerned with the work at the military base hospital at Dey in Algeria, where a department of physiotherapy had been established to meet the needs of the wounded soldiers during the war in Morocco. Before reaching this department the primary lesions of the soldiers had been cured, and the department was solely concerned with the secondary troubles, often very severe, such as: paresis and paralysis following on nerve lesions, 16 ; ankylosis or articular stiffness, 43; functional incapacity or atrophy, 3; total, 62.

In the 41 cases in which a definite result was obtained there was a complete cure in 51 per cent., marked improvement in 24 per cent., and no result in 24 per cent. Of the remaining cases 8 were invalided out of the service and 3 were placed on half pay. The writers claim that without the aid of physiotherapy the number of those permanently disabled and in receipt of State pensions would undoubtedly have been much increased. The methods employed were, in the cases of neuritis and wasting, the continuous current of high intensity with long séances, and sometimes in addition a current of rhythmically interrupted galvanism. For the arthritic lesions radiant heat and mechanotherapy were used. The chronic effusions were treated by radiotherapy, in pastille doses, every fortnight.

At the Radcliffe Infirmary, which forms one of the subsidiary hospitals attached to the Third Southern General Hospital, a very complete electrical installation has recently been added. The installation comprises Nagelschmidt's diathermy apparatus with a high-frequency attachment, a powerful American Baker 8-16 plate static machine, a Bergonié apparatus for obtaining electrically provoked exercises, a 500 candle-power leucodescent lamp for radiant heat, an electric light bath of 48 incandescent and four arc lamps, a Krohmeyer mercury vapour quartz lamp, two pantostats, and batteries, \&c., for rhythmically interrupted and reversed currents.

Of the 78 cases which have already been electrically treated 31 have been cases of frost-bite. Of these 24 have been discharged cured and 7 remain under treatment. (See Table). It is not suggested that these cures would not have occurred under other forms of treatment, or perhaps without any treatment, or even in spite of treatment. But it is claimed that by adopting electrical methods the most acute pain is speedily relieved, the stasis and swelling of the affected parts are reduced, the vitality of the tissues is increased, and in the necrotic cases the tissues are kept dry and aseptic,

1 Archives de l'Electricité Médicale, March 18th, 1913.

2 A paper read before the Congress of the French Association for the Advancement of Science beld at Tunis in 1913. whilst separation is hastened by the increased hyper. romia which follows the application of the treatment.

In frost-bite cases the form of electrical treat. ment is selected on the following principles. If the pain is very severe diathermy is found to give the best results. When the pain is very acute the treatment is commenced as soon as possible after the patient's arrival at the hospital, and in the more severe cases two treatments are given daily. In cases of slight frost-bite electrical treatment is not

Table showing the Number of Patients Treated, the Methods of Treatment adopted, and the Results to the Midale of January.

\begin{tabular}{|c|c|c|c|c|c|c|c|c|c|}
\hline \multirow[b]{2}{*}{$\begin{array}{l}\text { Nature of complaint } \\
\text { and number of cases. }\end{array}$} & \multicolumn{5}{|c|}{ Method of treatment. } & \multicolumn{4}{|c|}{ Result. } \\
\hline & $\begin{array}{l}\dot{\vec{g}} \\
\dot{g} \\
\stackrel{\Xi}{\Xi} \\
\stackrel{\vec{E}}{0}\end{array}$ & 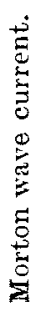 & 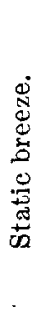 & 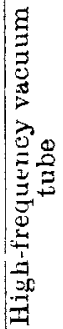 & 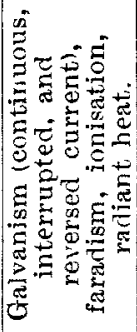 & $\underset{\stackrel{\Xi}{\Xi}}{\stackrel{\Xi}{\Xi}}$ & 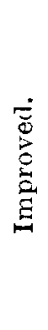 & 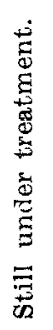 & 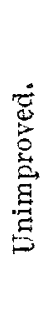 \\
\hline Frost-bite $\quad \ldots \quad \ldots 31$ & 20 & 1 & 12 & 7 & 1 & 24 & - & 7 & - \\
\hline Nerve lesions ... $\quad \ldots 22$ & 11 & 2 & 3 & 2 & 11 & 7 & 5 & 7 & 3 \\
\hline $\begin{array}{l}\text { R h e u m a t is m, } \\
\text { sciatica, neuritis } 10\end{array}$ & 3 & 5 & - & - & 2 & 3 & 2 & 4 & 1 \\
\hline Stiff joints, synovitis 8 & 1 & 6 & 1 & - & 3 & 3 & 1 & 4 & - \\
\hline Strain of muscles 4 & 2 & 2 & - & - & - & 3 & 1 & - & -- \\
\hline Eczema of $\operatorname{leg} \ldots \ldots \quad \ldots$ & - & - & 1 & - & 一 & 1 & - & - & - \\
\hline $\begin{array}{lllll}\text { Gout } \ldots & \ldots & \ldots & \ldots & 1\end{array}$ & - & - & - & - & 1 & - & 1 & - & - \\
\hline Sycosis menti... $\quad \ldots$. 1 & - & - & 1 & - & - & 1 & - & - & - \\
\hline $\begin{array}{llll}\text { Totals } & \ldots & \ldots & 78\end{array}$ & 37 & 16 & 18 & 9 & 18 & 42 & 10 & 22 & -4 \\
\hline
\end{tabular}

usually given, any slight pain which may exist usually subsiding with one or two dass' rest and warmth; occasionally, however, cases with no pain on admission develop a neuritis of the feet requiring electrical treatment a few days after admission. Cases which have lost sensation to heat are not suitable for diathermy, as there is a risk of the heat blistering them.

The following are the notes on a case in which diathermy was given in consequence of the pain disturbing the patient's sleep :-

CASE 1.-The patient was admitted on Dec. 17th, 1914. Was frost-bitten about the end of Novemier, whilst on active service in the trenches. He stayed in the trenches till Dec. 11th, when he was unable to endure the pain in his feet and reported sick. The pain had continued every night, disturbing his sleep. On the night of Dec. 18th there was considerable pain. Dec. 19th: Diathermy 10 by 5 c.m. electrodes, 0.9 ampère, for 10 minutes yesterday. There has been no pain since treatment, and the patient had good night. Dec. 20th : Diathermy repeated on the 19th. There is now no pain in the feet. The patient can walk well and is recommended for sick furlough.

Captain C.A. Coventon has kindly supplied me with the following notes of two of his cases which were treated by diathermy for severe pain in the feet following frost-bite.

CASE 2.-The patient was admitted on Dec. 31st, 1914. Frost-bite in both feet; very painful, preventing sleep. On Jan. 1st, 1915, he was admitted to Radcliffe Infirmary for electrical treatment. On the 5 th there was much less pain, he slept well, and there was more movement. On the 6th he continued to improve, was now quite well, and was discharged to sick furlough. The electrical treatment in this case seemed to cause immediate improvement, the pain ceased, and convalescence went on uninterruptedly. 
CASE 3.-Frost-bite in both feet. The patient was admitted on Dec. 31st, 1914, with great pain necessitating morphia ; there was no great discolouration and very slight movement. On Jan. 3rd, 1915, he was admitted to Radcliffe Infirmary for treatment by Captain Turrell. On the 5th the pain was much less, he slept through the night, and had much more movement in the toes. On the 12 th he con. tinued to improve. On the 14th he was discharged to sick furlough. The remarks on the improvement of the other case equally apply to this one.

The so-called cases of trench pain or trench feet usually have no tissue destruction, no blebs, and not even any discolouration of the skin; they would appear to be due to acute neuritis of the feet excited by cold and exposure. The most acutely painful case we have treated was of this nature. The day after admission the patient was writhing in bed with agonising pain, his hands clenched, his face buried in the pillows, his face and feet covered with perspiration, there were no physical signs of any lesion. This patient was the only one we have treated who derived little or no benefit from diathermy; on the third day of his treatment the diathermy apparatus was temporarily out of order, so he was treated by the static breeze instead. He was immediately relieved, slept the whole of that night, and only had a slight recurrence of pain on the following day and this was relieved by a repetition of the treatment. The patient had no further relapse, and two days afterwards was walking about the ward. The other patients who have been treated by both methods have always stated that their pain has been more relieved by the diathermy than by the static. This patient was suffering from considerable nervous exhaustion, and probably a great part of the benefit he derived from the static breeze was due to the constitutional effect of this treatment.

Cases with no ulceration, but with blebs, and cases with loss of sensation to heat, we find respond best to the high-frequency vacuum tube. It is remarkable how quickly the blebs dry up under this form of treatment. Where there is ulceration and necrosis the static breeze with the patient negatively charged is the best form of treatment. The worst case of frost-bite which has been admitted to the hospital has been under treatment for about six weeks by this method. On admission the toes were hard, dry, and withered, the sole of the foot was covered by a large black bleb, on the dorsum of the foot a line of demarcation was already appearing about one inch from the base of the toes. The static breeze has been applied daily, and pain, whenever it has occurred, has been relieved by the treatment. The toes are now separating at the metatarso-phalangeal articulation. The granulations are very healthy in appearance, the wound has kept perfectly aseptic, and only on one occasion has the temperature risen to $99^{\circ} \mathrm{F}$. The patient's general health has much improved. The cdema and induration on the dorsum of the foot have nearly disappeared.

The rationale of the static breeze in the treatment of frost-bite is apparent from the following description by Dr. Benham Snow of the thera. peutic action of this modality: "The effect upon local stasis ..... where swelling and induration are present is to generally soften the tissues. This is due to the action of the discharges producing recurrent contractions of the tissues, thereby inducing an onward movement of the blood current through the vessels. Over superficial odema ...... and where ecchymosis is present the effect of these applications systematically applied is remarkable in its results ...... To ulcerated surfaces the appli. cation of these modalities is one of the most valuable in therapeutics. Applied over the indu. rated margin, where it has a positive effect in relieving stasis, it proves to be of the greatest value for the relief of those conditions. The cir. culation is restored throughout the zone of indura. tion, which surrounds the ulcer, when a reparative process is immediately instituted.'

Several patients have been treated on account of very severe pain in the extremities following crush. ing or partial division of a nerve. It has been found that diathermy has always afforded marked relief; after the first treatment the pain is usually absent for four or five hours, and subsequent treat. ments result in a longer period of relief. In treating patients with very severe pain two applications of diathermy are administered daily, the second one being given as late as possible in the evening, Treated in this way patients who previously had only experienced brief relief from hypodermics of morphia sleep through the night without pain. Diathermy does not appear materially to shorten the period of convalescence in these cases, nor does it prevent the occurrence of trophic changes in the skin. In order to keep the patient free from pain the treatment has to be continued in some cases for two or three months. Often when the treatment is omitted for one day the patients complain that they have missed it and have had more pain.

In cases of nerve degeneration, if the mischief is slight, and the muscles react to faradism, the rhythmically reversed faradic current is used. Where the faradic reaction is lost, when there is no pain associated with the lesion, rhythmically reversed galvanism is used; when pain exists rhythmically interrupted galvanism is selected. For testing electrical reactions the condenser method is used and is found to be not only much quicker, but also to give more information in regard to the degree of nerve degeneration than the faradic and galvanic methods.

Sprains of muscles and synovitis of joints usually yield readily to the Morton wave static current, and the patient's stay in hospital is generally materially shortened by this treatment. The Morton wave current, either alone or in association with ionic medication, is used for the treatment of stiff joints.

The following interesting case of " spinal concus. sion" speedily yielded to the persuasive influence of Bergonié's machine for electrically provoked exercises. The rapid cure will probably be attributed to electrical suggestion, but in view of the vigour and amplitude of the muscular con. tractions excited by this apparatus "electrical demonstration" might be a better term.

CASE 4.-The patient, whilst serving at the front, was driving an ammunition wagon when a shell exploded under the wagon, killing one horse and severely wounding the other. The patient states that he was blown several feet into the air, and on falling dragged himself to the shelter of a hedge, where he remained all night. The following morning he could neither walk nor stand. On being taken to the medical officer the patient states that pins were pushed into both his legs without producing any sensation. On admission to the Third Southern General Hospital the patient appeared to be unable to draw up or move his legs or to stand up. The reflexes, sensation, and electrical reactions were normal. After a few days' rest in bed the patient could walk a few steps with assistance; he was then transferred to the Radcliffe In. firmary for electrical treatment. He was there treated 
by electrically provoked exercise to the back (positive) and seat and thighs (negative). After the treatment the patient walked back to the ward by leaning on his wheeled chair; on the following day he walked to the electrical department with the aid of sticks, and after a repetition of the exercises he walked without assistance. On the third day the Morton wave current was applied to the back to clear up any remaining stiffness. No further treatment was required, and the patient was discharged on sick furlough. Oxford.

\section{FEAR AND DISEASE.}

BY E. T. JENSEN, M.B. LoND., M.R.C.S., L.R.C.P. PHXSICIAN TO THE SPECIAT, HOSPI'AA FOR OFFICERS, KENSINGTON PALACE GREEN.

Toxis formation and the physical effect of toxins on the organism have been investigated both bacteriologically and dietetically as the cause of alimentary toxæmia, but we are still searching for that fundamental factor which allows the toxins to enter the blood in excessive quantities. I wish in this paper to put forward a hypothesis showing that this fundamental factor is, either partly or entirely, the direct result of a mental state. Dr. E. Mellanby raises this question when he says ${ }^{1}$ :-

The key to the situation is not held by a consideration of the bacteria of the intestine, nor of the chemical endproducts of bacterial action, but rather by knowledge as to the normal methods of intestinal absorption, and more particularly of the mechanism which prevents the passage of toxio substances across the mucous membrane into the blood-stream. [Italics are mine.] The important question is: What is the cause in acute intestinal disturbance which brings about the breakdown of the defensive mechanism and allows the entry into the blood stream of toxic substances?

Dr. Murray Leslie seems to emphasise the same question when he says ${ }^{2}:-$

It seems to me that sufficient stress has not been laid by previous speakers on the first factor-namely, the power of resistance on the part of the individual. It is true that reference has been made more than once to the fact that there is no necessary relationship between the amount of stasis and the degree of toxæmia. It is a matter of daily clinical observation that some persons can remain constipated for days, and even weeks, without apparently suffering any ill-effects, while in other instances the missing of the usual after-breakfast evacuation is invariably followed by headache, malaise, and inability for phyaical or inental exertion. Habit-tolerance, important though it may be, does not altogether account for such phenomena. There seem undoubtedly to be individual idiosyncrasies in respect of liability or resistance to toxæmia. The importance of the personal factor is exemplified by the well-known liability to bacterial invasion (including bacillus coli infection) of persons debilitated by injury, disease, over-fatigue, senile tissue degeneration, and other conditions leading to diminished vital resistance. Thus, for instance, it is known that shortly kefore death, when the vital protective forces are more or less in abeyance, the bacillus coli and other bacteria can freely pass through the intestinal mucous membrane and so into the circulation, while their toxins, not being neutralised or destroyed, accumulate in the circulating blood, and are no doubt responsible for many of the symptoms preceding dissolution, including antemortem pyrexia. Metchnikoff, indeed, believes that such absorption is the primary cause of death in most cases of senility, while any check to such absorption tends greatly to prolong life.

I am led to believe that, in some of these cases at least, nervous worry and all the emotions of an unplesant character, which I summarise generically as fear, are frequently a direct cause of alimentary toxæmia. Under the heading of "fear" I group

1 Proceedings of the Royal Society of Medicine, 1913, vol. vi., p. 250. Ibid., p. 267. broadly all such emotions as may contain an element of fear, such as anxiety, sorrow (a present loss, with fear of unhappiness in the future), overwork, anger (fear of another), exaggerated selfconsciousness (fear of criticism), and pain, with its milder varieties of malaise and fatigue. Fear, in its generally accepted sense, or any excitement of an intense and unplesant nature, will commonly result in pallor with a feeling of faintness, while gastrointestinal and vesical disturbances frequently ensue.

What are the physical causes of these effects and, if these causes persist, how is the organims affected? Compare the physical signs of fear with the results of shock. During abdominal operations shock effects are sometimes manifest and have often been described. Here the intestines become deeply injected, increase in volume, and may finally emerge from the body cavity. This distension is not due to the formation of gas; it is paralytic. The vaso-constrictor fibres of the splanchnic area are paralysed, and similarly those whose function is to maintain visceral tone. The face becomes pallid from the fact of the blood leaving the head to fill the vessels of the mesenteric area, blood pressure is lowered, and if shock is severe or continued the heart may stop. Short of this last, the following conditions, by reason of this dilatation, then obtain: (1) The absorption area of the inner intestinal surface is greatly increased; (2) the absorbing area of the blood-vessel wall is also increased ; (3) the intestinal wall is thinned ; (4) the walls of the blood-vessels are thinned; (5) they contain more blood; and (6) the blood stream is slowed, remaining longer in the absorption locality. Now we have on the one side of the intestinal wall blood (and lymph), and on the other side food and toxins. All these six factors tend, by the law of osmosis, to farour absorption of the intestinal contents into the blood. Is it not therefore probable that the same condition, to lesser degree but for longer duration, is induced by the shocks and resultant fear complexes incidental to most lives? Truly more food may at the same time be absorbed, but prematurely, in that case, further increasing the waste products to be afterwards eliminated. In any event, the toxin rather than the food question here holds the field.

I submit that the effect of fear will produce to some extent the same condition of intestinal collapse observed in surgical shock, slight possibly in degree, but sustained if the cause persists, and further that this loss of visceral tone tends, in the erect posture, to cause a drag on the visceral nerves (which cannot stretch as much as the gastric and in. testinal muscles) and enhances the shock effect. We note that in order so diminish this factor and lessen the heart's work the subject prefers to lie down.

A patient describes how the sight of an accident affects his stomach. He develops wind immediately and his heart becomes embarrassed. He has an "all-gone" sensation in his abdomen. Here again one can only believe that a sudden paralysis of gastric and probably of intestinal muscular fibres allows the expansion of gases already present, and that dilated viscera now press on the heart. As the emotion passes the tone of his intestinal tract returns, and the expulsion of wind from the stomach often completes his recovery. A man bracing himself for an ordeal instinctively tightens his belt (girds up his loins). He feels a vague need of abdominal tone and has a sense of power (courage) when this manouvre has been carried out. Atony and flatulence may, I believe, be 